\title{
1. The noose of competitive accountability
}

Over the course of the last decade my work has focused on the effects of higher education (HE) policy innovations on academic researchers working in UK universities. Specifically, I have looked at the discrete yet frequently conjoined if not conflated policy areas of public engagement by academics and the economic and societal impact of academic research. What feels like and surely is a surfeit of studies later, I have learnt, often with brutal and discomfiting immediacy, much about academics' struggle, perhaps even their crisis, in making sense of who they are and what they do in the face of such alleged innovation and in a milieu where their professional lives have become in many instances hostage to the whimsy endless intrusion, interruption and intervention - of higher education technocrats. A crisis of academic personhood spun off from a giddying and ever-quickening carousel of policy permutations is also explained by many if not most senior academics - and therefore those who might contest or resist change - having meekly bowed to the aggressive expansionism of an 'administrative estate' (see Ginsberg 2011) and the cognate seductions of neoliberalism. Many academics, certainly those of a particular vintage, talk apologetically - and therefore often excessively and with a bias born of nostalgic indulgence - of having had their powers and rights to self-determination and expression seized by a massing rank of managerial Übermenschen. They claim to suffer the injustices of marginalization, disenfranchisement and banishment to the outer realms of their institutions, the universities over which they once presided and exercised government. Their authority is seen to have waned, their critical agency and political capital eroded. They have become mere bit-parts or walk-ons to the drama of which they are (at least listed as) major protagonists. 
Academic life on the contemporary stage is thus a life on the fringes, yet a life on the fringes no less visited upon by forces of economic determinism, corporate indoctrination, and the esurience and tyranny of managerial plutocrats. Where not excommunicated, academics are represented as docile subalterns to an administrative elite who with obdurate efficiency police the transition of the university from Humboldtian pasture to Kafkaesque fortress. They are also seen to be implicated in a game of self-deceit and the suspension of disbelief - where so many of the behaviours they affect, the deeds they perpetrate and the roles they perform are antagonistic to the values they espouse.

Great swathes of writing have already been committed to an ongoing and seemingly endless discussion of how the identity and role of the academic have depreciated in tandem with the reordination of the university from bastion of intellectual endeavour to engine room of capitalist enterprise. My aim in these pages is to unfasten and progress this critique. The offering is one of mediation or perhaps remediation of academics not via foolish idealism and profligate summoning of a perfect past that never did exist or by asserting the extent to which they have been victimized but by seeking a reconceptualization of what academics might be, set against a consciously critical observation of what they currently are. This demands an engagement with what is essentially a recent history of cultural transformation in academia, though not a preoccupation with a valorization of its past, no matter how parlous present circumstances appear. A reconceptualization, however, of what academics might be depends on academics being willing to honestly and openly confront and accept perhaps less what has been done to them and more what they have (albeit unwittingly) allowed themselves to be used for.

Thus, my explicit hope is to illuminate the great absurdity that characterizes the way academics in the grasp of recent and ongoing systemic transformation (in many parts voluntarily) find who they are and what they do changed. In the following pages I will seek to situate the root of academics' alienation from the fullest potential of who they aspire and claim to be by laying bare the 'inauthenticities' of their self-presentation. I will expose the dramaturgical effects that distort a sense of who they genuinely are, which obscure their limitations, yet which ironically contribute to the enervation of their self-concept. I will ask who academics are beyond their tightly 
choreographed and coiffured public presentations - and who they might be - where they profess through their scholarship a profound public contribution yet where such a contribution upon closer inspection is other and far less than that professed.

The standard neoliberal critique of higher education or, rather more pointedly, academics' decline has become tired and stultifying. It provides only a means of blame or apology rather than a means of volition. In fact, an insistence that academics are victims of agency-theft has become as predictable and superficial as their affectations of (countercultural) otherness and entirely arrestive to any 'true' transcendence or cultural metamorphosis from 'soft' versions of their self-concept, a softness made and exacerbated by a willingness to simultaneously conform and feign defiance. And so it would seem that breaking this deadlock requires self-confessional. It requires that academics challenge and confront easy and convenient assumptions of themselves. It demands that provocative and perhaps uncomfortably revealing questions concerning personal motivation and choice and the limits of resolve against the seductions of the market are answered. It requires that academics surrender any preconceptions of their own exceptionalism as virtuous agents (Nixon 2008) and of their 'contribution' as sui generis. In short, academics need to relinquish the urge to perform in the spotlight of what I will call 'competitive accountability' and lay themselves bare to another form of scrutiny which is entirely their own. This may just be the big bang moment, where an alternative universe of academic praxis becomes not only apparent but sustainable. It may not be the start of the recovery of an idea but the beginning of a new one.

A new idea of academic research and of the academic researcher as publicly accountable, salient and beneficial thus begins by exposing the manifold ways in which academics in very many ways are categorically not, though nonetheless are presented to be. This becomes the function of this book, which focuses on exploding contemporary mythologies of research life in UK academia that are explicitly bound up with representations of the public role and contribution of the academic researcher. And, while being UK-centric, this is a book replete with implications and warnings for 'scientists' of every denomination working in other comparative HE temporalities, especially those where a conversion to market logics may be easily accomplished or a near reality, and where 
efforts to rationalize the public value of research have been prioritized. We witness at first hand numerous attempts, by a range of international organizations such as the US National Science Foundation and European Research Council and governments in countries such as Australia, Finland, Sweden, the Netherlands and New Zealand to name but a few, at defining the contribution of research apropos of its 'benefits to society' and 'beyond academia' (Derrick 2018; Grant et al. 2010).

What then follows is an account of how a pressure to perform and satisfy the economic and societal expectations of a marketized yet mainly publicly funded system of higher education engenders among academics - and certainly their institutions - forms of behaviour that are antagonistic to archetypal ideals of scientific practice yet are excused or obfuscated on the basis of political pragmatism and expediency. This confluence of market principles with public needs produces a culture of competitive accountability among academic researchers. I will argue that a culture of competitive accountability stimulates performance-based anxieties that are corruptive to academics' self-concept as active contributors to the public sphere - and therefore debilitating to their effectiveness as 'public intellectuals' - which in turn engenders inflated or otherwise counterfeit rationalizations of the public value of academic research. In this given scenario, academics are ensnared by the vice, or it may be the noose, of competitive accountability. Yet, before further sketching this image of the contemporary UK university as an academic-gallows, let me first unpack some of the complexity and compositeness of what is meant by 'competitive accountability' before a consideration of academics as public actors, as public intellectuals.

\section{COMPETITIVE ACCOUNTABILITY}

The conversion of UK higher education into a performance management regime has instigated what Michael Tomlinson and I have termed a culture of 'competitive accountability' (Watermeyer and Tomlinson 2017) among academics in UK universities. This we define as the way academics provide an 'account' of their role and contribution as researchers and teachers that privileges not academic or intellectual but market-driven values. The aim of academic 
labour in the present time of higher education's marketization is rationalized therefore not so much by a traditional concept of intellectual endeavour - reflected in Mertonian ideals of autonomous and disinterested science or higher education as one part of a project of social democracy (Merton 1942) - but by academics involved in leveraging 'positional goods' (Hirsch 1977) into their universities. This is achieved through a commercial sensibility and a willingness to commit to diluted or ersatz appropriations or simulations of typical academic functions of teaching, research and what has become known as 'third-mission' activity - activity directed towards the fulfilment of universities' 'civic' responsibilities (Goddard et al. 2016). In higher education's 'prestige economy' (Blackmore and Kandiko 2011) a focusing by academics on market deliverables offers a more efficient and cogent means of justifying their 'societal' worth and by extension their patronage by the public purse. Yet this has resulted in a 'dialectical dance' (Sutton 2015) between an aspiration of critical autonomy and detachment and an actuality of instrumentalization and subservience to political and economic needs. It has in other words produced what Paul Sutton (2015: 37) observes as an 'oscillation between fatalistic disenchantment and utopian hope', or what I think of as an impasse to a renegotiation of the terms of academic praxis - or, as is the primary concern of this book, the role and contribution of the academic as researcher and public intellectual.

This dance between an actuality and aspiration of academic life or academics' capacity for 'reflexive interplay' (Henkel 2001) appears, however, increasingly immobilized, where academics, especially a new generation of academics, are naturalized into a 'performative' (Ball 2012) mindset that counteracts their faculty for critical perception. Thus, an inequity eye is blinded and, as Henry and Susan Giroux (2004: 232) rather damningly put it, academics convert with little to no resistance - or worse without knowledge of a need for resistance - into "entrepreneurs who view the future as an investment opportunity and research as a strategic career move rather than as a civic and collective effort to improve the public good'. While such a characterization of academics' transmogrification into market players is far from being a universal truth, the ease of academics' reappointment in the 'new economy' (ibid.) that it communicates is hard to contest. The identity and role of academics appear vastly diminished from the potential of their 
contribution as public intellectuals - and their contribution has been curtailed to the (regulated) supply of education as a high-value commodity.

Of course, the dialectical dance may no more aid than encumber academics, at least those awake to the perniciousness of their reappointment. Arguably then neither critical somnambulism nor the strict polarization of academics as disciples of either despondency or fictionalized futures will help to break the deadlock. A middle way is surely lacking. Yet, as I will argue throughout this book, locating a middle way requires academics to first be alert to, cognizant of and accepting of the folly of acceptance of the terms of their reappointment. What follows then is a demythologization of academic praxis or what Freire (2007) termed a process of 'conscientization' - a stripping back to and confronting of the realities of contemporary life in academic research (no matter how discomfiting or additive to a sense of vulnerability) for the purpose of inspiring social action and transformation - which chimes with a lot of neoliberal critique yet attempts to dodge what so often transpires to be its paralysing effect and the arrestive bifurcation of academics into the locked categories of hopeless misanthrope and reckless optimist. A middle way comes instead, ostensibly, from the coalescing and blending of the two, a synthesis of these paradoxical parts of the academic psyche. The realization of a better academic world - and the transference of dreams into realities - would seem to stem therefore from what Bloch (1986) termed 'educated hope': an acknowledgement and honest appraisal of the material conditions that determine the plausibility and efficacy of academics as agents of social change. Consequently, academics might resist the disempowering and apathy-inducing effects of an altogether too easy (and increasingly acceptable) descent into a state of professional victimization (see Furedi 2004) which, perhaps quite reasonably (and obviously to some), may be attributed to the dehumanizing effects of universities' hyper-bureaucratization and analogous deprofessionalization of the academic profession. Yet the prospect of 'educated hope' would seem to rest with an assumption that the 'diminished self' of academic identity is fixable, that the self-concept of academics isn't entirely broken, and that selfactualization in the milieu of academics' automatization in the 'knowledge factories' (Aronowitz 2000) of higher education is possible. There also seems an urgent need to locate the self in the 
context of the potential of a community of selves enacting social change and engendering new material conditions from which academic identity might be (re)cast.

Much of the speed and success of academics' reappointment seems connected (through either indoctrination or enforced conversion) to their siloing as 'independent' knowledge workers. Yet this is not an independence in the sense of critical autonomy but independence from each other. The performative turn has caused academics to lose sight of their community where the pressures of competitive accountability pit them against each other in a perpetual game of one-upmanship and struggle to prove who's best or who can claim a greater portion of 'excellence' - that most excessively dumb and empty of qualifiers. UK academia now seems almost to suffer from an employee of the month syndrome, such are the pressures to perform, with academics consistently trying to outpace and overtake each other. Indeed, a sense of self-worth and achievement is often (erroneously) calculated not by self-reflection but by comparison to the achievements of others, an act regrettably made all the easier by the 'digital shopfront' of academics' personal webpages and the constant and unnerving avalanche of social media reminders that with trumpet fanfare announce that $x$ from $y$ university has produced yet another new publication. Yet a sense of community and of social belonging has been lost where academics' self-concept has become - one might venture in such a way as to benefit and befit easy governance - loose and uncertain. In fact, in the 'accelerated Academy' many academics seem plagued by an unrelenting fear that their own contribution is - if only in volume inadequate. This vulnerability may be especially acute where academics feel not only 'outperformed' but that they are deemed to 'underperform' in light of a contribution far less - if in number only - than the output bounty of their hyperactive and mass-producing counterparts.

In the UK, the Research Excellence Framework (REF), a national performance-based research funding system (PBRFS) (discussed at length in Chapters 2 and 3), the last instalment of which ran in 2014 with the next due in 2021, has caused academics to rethink themselves or think of themselves exclusively in terms of output or numbers of outputs - and, as will be discussed, the 'impact' of these outputs. For many (REF eligible) UK academics the concern will be: 'Have I reached my REFable quota of outputs?' - and this 
is regardless that the rules of the REF have been relaxed apropos of quota expectations: from a minimum of 4 outputs in the census period (typically five to seven years) to an average of 2.5 (though it's not clear what half an output constitutes) or minimum of 1 . For departments and/or those in the process of REF preparation the question will be: 'Can we as a collective reach the magic number of outputs that will return to the institution a good share of qualityrelated (QR) research funding, of which the UK government through its various higher education agencies administers somewhere in the region of $£ 2$ billion annually, and moreover keep us all in post?' For the uninitiated in REF, the rules that feature in its second instalment have been reshaped and reflect something more of a humanitarian approach to research evaluation, where most, not just some, academics are included, this being a policy of universal submission. Yet universal submission, whilst appearing inclusive, does not remove from the REF the threat of academics appearing not quite REFable and therefore not quite legitimate researchers. It does this through saying that, while academics need to submit a minimum of 1 output and an average of 2.5 , they might also submit up to 5 outputs. Thus, it becomes easily imaginable that certain high-performing (and highly productive) individuals will be prioritized for their five $4^{*}$ publications, letting others off the hook, where they need return just the one. How easy will it then be, if it has not already come to pass, that the REF will continue to stratify researchers and replicate the same kinds of social divisions, bias and exclusionary hierarchies that characterized much of the complaint levelled at REF2014? More of this is to come.

Outputs aside, one of the most significant developments of the REF, not previously formalized in its predecessor, the Research Assessment Exercise first initiated in 1986, has been the introduction of impact or more specifically the economic and societal impact of research as a measure of performance assessment. Impact in the REF, represented by academics in the form of narrative case studies, has assumed huge significance for universities because of how it influences an overall REF score and also because of its contribution to the return to universities of QR. It is through REF impact that academics working in UK universities provide an account of the 'return' on their public investment. It becomes therefore the most prominent means by which academics practise 'accountability' to the public as research sponsors and financiers. 
However, it is also what produces a deviation from a 'true' sense of public accountability, where, as a constitutive part of a PBRFS, practising accountability occurs in the context of and as a part of research competition and universities' competitiveness. Competitive accountability is accordingly used as the conceptual stage from which an account of universities' systematic manipulation of the REF, and specifically REF impact, as a technology of research governance is built and from where a story of academics' dwindling agency, authority and legitimacy as public intellectuals - a definition of which I now consider - arises.

\section{THE PUBLIC INTELLECTUAL}

If UK academics now exist in an era where the quality of their intellectual contribution is decided upon and made analogous to the quality of their intervention in the public sphere, and if, as appears to have been the wish of research funders (as the proxy of government) in their determined efforts to embed a culture of public engagement in UK universities (see Watermeyer 2011), research needs now to be publicly engaged in, then the logical assumption is that academics - certainly those normalized into such a cultural mindset (and typically early-career) - are evolving into public intellectuals. Wrong. While academics might certainly be seen (to perform) in apostasy to the 'ivory tower' and as trying to integrate or at least penetrate into their public communities, the extent to which they may legitimately claim citizenship as 'public intellectuals' is less assured. This may be attributed to at least two factors. Firstly, an assumption that all academics operate or think of themselves as intellectuals may be, if not false, at least fragile. Many academics think of themselves as just that, academics, or in other words as individuals who are professionalized providers of academic solutions to academic tasks, tasks crucially that are set and demanded by the institutions by which they are employed (which also provide their professional training). These tasks tend to cohere around three main missions: research, teaching and administration; 'administration' tends to be a catch-all term into which many will fold what is often described as 'third-mission' activity (public engagement, outreach, etc.), which in many cases tends to be limited to institutional marketing and public relations activity 
(and is certainly located in such divisions or departments). Not one of these missions necessarily requires an intellectual contribution. For instance, researchers - I know many - may be highly competent research technicians. They may be able to design and implement research projects and produce robust evidence. They may not necessarily, however, do this in any explicitly critical fashion, which would seem the defining quality of the intellectual. They may instead be apolitical, politically timid or without political conscientiousness or agency. As academic researchers they may be far removed from or intentionally avoid integrating their role as researchers and therefore knowledge experts with a role as social or political activists - with such a convergence being not only, no matter how obvious, the preserve of the social sciences or arts and humanities; in fact, critical conscientiousness and social activism may be far more observable and abundant among researchers within the 'sciences'. Secondly, this hypothesized dearth of 'political agency' among academics and/or lack of critical ambition may correlate to the extent to which academics are institutionalized, operate in accordance with institutional parameters, and are extraordinarily far from operating in any public fashion, where the tasks they are assigned are institutionally formalized and for the most part completed in-house. In sum, research academics may, where they are trained and contained by their institutions and where they are without prospect of convergence or exchange between their role as in-house technicians and social activists, be the inverse of "public intellectuals'.

Of those who have discussed the invisibility or disappearance of public intellectuals, a theme of intellectual institutionalization or the absorption of intellectuals into 'fattened' and 'bloated' university structures looms large. Russell Jacoby (1987: 6), for instance, attributes an intellectual evanescence to a 'magnitude of cultural restructuring' and of universities having 'virtually monopolized intellectual work'. He speaks of a 'complete renovation of intellectual identity' (1987: 18) where so-called intellectuals, institutionally homed, become utterly preoccupied with the challenge of building a university career and rarely venture or have ventured outside ${ }^{1}$ the walls of such a privileged sanctuary. In their professionalization academics have relinquished a dialectical duty, which Edward Said (2002) sees as informing 'the intellectual as lookout': s/he who speaks truth to power and intervenes to elucidate and confront the 
emasculations of normalized or unobserved hegemony. Too focused on looking in, academics have arguably become desensitized to societal injustices and abuses of power their knowledge might otherwise detect and defeat. Too much internalized, too far assimilated and homogenized, academics have become estranged from a duty to dissent and to wilfully contest and/or conflict with authority, which has culminated in the obfuscation and unchecked distension of unequal and unjust regimes and, moreover, the kinds of capitalistic rapacity now endemic within universities.

In the writings too of Robert Nisbet (1996) is communicated directly the abandonment of intellectual ambition, what he calls the 'degradation of the academic dogma', and its succession by capitalistic motivations and interests. These are now relatively old writings, which alongside others such as those of Roger Kimball (1990), Allan Bloom (1987) and Richard Hofstadter (1963) centre on the erosion, depurification or disappearance of the intellectual as a public figure, yet they are no less relevant in the context both of the professionalization and institutionalization of academics in a market economy of higher education and of the current political context of the United Kingdom and the United States and a violent swing towards populism represented in the dual contexts of Brexit and Trumpism.

In the UK context, the significance attributed to expertise and evidence, so central to the policy-making ethos of New Labour and articulated in a vision of evidence-informed policy, has been to a large degree relegated by and replaced with the demands of demagoguery - and a sense that 'the people', not politicians or their experts, know best. Much of the dwindling trust in expertise may be explained if only in part by reference to the events of global economic catastrophe in 2008 and an argument that all those who should have known about and would have been able to predict and forecast such events failed to. In such a way of thinking the apportioning of blame seems in an extraordinarily imbalanced fashion to have settled squarely on those whose scrutiny of power and the powerful had their radar either switched off or at best working below par. The accountability of the mainly invisible and therefore untouchable profit-mongers of high finance - whose insatiable greed and social apathy instigated misplaced trust in a (failed) politics of austerity and analogously the near complete devastation of the welfare state - never materialized. Yet, while 
'experts' have carried the can, there seems to have been little discussion of why they were so wide of the mark and off-target. One potential explanation is that they were just too close, too involved, too active, too enmeshed and too invested (with too much to lose) as players within a power-elite. The extent of their harmonization - or appropriation - might thus have weakened the degree to which they could and would call power to account. Their failure in this respect may thus explain the ease of their implication as public scapegoats and the strength of a rationale for the intensification of their own surveillance. If experts were centrally responsible for such an enormous faux pas, what other things might they be getting wrong and what consequences of other misadventures might be faced?

Moreover, much of a tilt away from academic expertise and a corresponding prevalence of anti-intellectualism may be attributed to both a moral and an economic investment in knowledge democratization processes, with technological innovation facilitating the global distribution of information and thus the proliferation of knowledge receivers and users, and ostensibly increased numbers of more highly educated and therefore potentially politically literate or at least active citizens contributing to and building the public sphere. However, conversely, technological innovation might open the door to a new space - or infinite spaces - for public intellectualism that might reverse the temporal dislocation and 'decline of bohemia', the likes of which Russell Jacoby (1987) discusses, and therefore universalize or at least diversify the identity and ownership of intellectual endeavour, at once breaking academics' jurisdictional claims. Yet this digitalization of the public sphere may also provide opportunities for academics to merge or transition between their academic and activist identities and therefore solve the problem of their institutionalization. The opening of the 'digital agora' and what I will argue to be 'powerful peripheral zones' of academics' (non)participation may thus emerge as a remedy to their being lost as public intellectuals. This may be no easy remedy, however, as academics find themselves catapulted into a liminal, contingent and largely open space, where an academic's voice is one among a polyphony of voices.

Where academics are prevalent in the public sphere they exist particularly in the REF impact milieu, as minor celebrities. Their role as public intellectuals has essentially been adapted and made 
fit for consumer or essentially media culture. They have as public intellectuals been marketized. Intellectuals going public in the contemporary milieu thus in most instances constitutes an interface with or through the marketplace motivated by competitive accountability. The twenty-first century's public intellectuals may be lured by the prospect of having their work and expertise showcased in public forums - aired on radio and television shows - in a game of fame in which they are encouraged and receive rich reward from their institutions, certainly in terms of REF impact, yet also perhaps more importantly through which they can stabilize their selfconcept. There is in this a suggestion that the contribution of public intellectuals may be disingenuous and linked not by a desire to translate their ideas into political action but to exchange their ideas for political currency. So too comes a notion that a collusion with the market enervates the status of intellectuals as non-partisan and independently critical (some would have it, aloof), which would therefore also jeopardize their credibility. Yet this also assumes an unrealistic conceptualization or expectation of intellectuals, certainly in present times, as political outsiders, politically unaffiliated, or passive and indifferent to political activism - their role being exclusively the voice of opposition. Instead, as Andrew Ross (1993) has argued, their role may be as much conflictual as cooperative, where they are at once stridently unattached and committed only to dissent, yet at the same time are advocates and proselytizers, the face and voice - perhaps the 'poster boys and girls' - of insurgent movements.

The question becomes in the risk-averse Academy the extent to which competitive accountability dissuades and/or disables academics from invoking their political agency, where such forms of public enactment may be disadvantageous and potentially damaging to their institutions' branding and therefore their own careers. In other words, where academics as a new precariat have become so dependent upon (and regulated by) their institutions not only in terms of their economic livelihood but in the context of their self-concept, their intellectual ambition is controlled, contained and perhaps in many cases cauterized. The institutionalization of academics may be thus inextricably linked to the obsolescence or death of their aspiration as intellectuals or the categorization of academics as intellectuals, at least where the concept of the intellectual as knowledge mediator is defined by her/his political (or institutional) 
detachment and critical agency. Concurrently, intellectual exhibitionism is ubiquitous, with a myriad of social actors, the vast majority not academics, contributing their thoughts and ideas in a public sphere, the technologically facilitated massification of which has loosened the qualification of what it is to be an intellectual so much that it is virtually meaningless. Certainly, academics may no longer claim majority rights. As Edward Said (2002: 22) has argued, the proliferation of platforms from which a plurality of 'intellectuals' may speak has resulted in public discourse becoming 'densely saturated'. The contribution of an academic intellectual discourse - which might be mainly associated with the social sciences and humanities - finds its perch in a sea of voices further destabilized by 'its generally hermetic, jargon-ridden, unthreatening combativeness' (Said 2002: 23). The extent then to which academics might genuinely penetrate, inhabit and contribute to the public sphere is hugely open to question.

\section{STRUCTURE OF THE BOOK}

The extent to which competitive accountability delimits or actually deletes the opportunity for and efficacy of academics' acting as public intellectuals, as experts working in the public interest, is the core business of the following chapters, which consider how academics' public citizenship has been institutionalized, instrumentalized, regulated and controlled, and ultimately hollowed out. Crucially, these chapters are not intended to induce further desperation or sense of defeat but act as provocation for change, with the weight of such provocation drawn from empirical data collected over a three-year period. These data span the experiences and views of REF impact case study (ICS) authors, REF impact evaluators, and REF impact receivers, and therefore the book employs a multi-perspective, perhaps even a 'whole-community', approach to problematizing REF impact and therefore, by extension, the influence of competitive accountability on academics' research praxis. I add to this my own professional experience and knowledge gleaned as a seasoned evaluator and researcher into public engagement in science and technology and wider higher education contexts in addition to my experience as a policy and media analyst and academic middle manager. This is wrapped in what is in parts an 
explicitly sociological analysis and the application of social theory in order to make sense of competitive accountability as that which influences, informs and characterizes research praxis. Discussion is also largely biased towards an understanding of competitive accountability in the contexts of the social sciences and arts and humanities disciplines, though the transferability of core messages in considering how competitive accountability plays out in other disciplinary contexts should not be dismissed.

The book is arranged into three core groups of chapters. Chapters 1 to 3 provide a critical conceptualization of the political, economic, social and cultural dimensions of intellectual life as influenced and informed by competitive accountability. Chapters 4 to 6 constitute the empirical heart of the book and the presentation of original data that elucidate the manifold problems of a higher education system organized by competitive accountability. Thereafter, Chapters 7 and 8 locate a problematization of competitive accountability in the context of direct and ongoing challenges to the economic valuation of university management and rank-and-file academics and an overall synthesis of core concerns from which also stems a call to action.

In more specific terms, Chapters 2 and 3 consider the configuration of competitive accountability in terms of the REF's policy generation and evolution and the frailty of academics' response and resistance to it. While Chapter 2 suggests that competitive accountability in the REF is something academics love to hate, Chapter 3 introduces ideas concerning the feasibility of intellectual endeavour beyond and in resistance to the neoliberal university and in a digitalized state of post-institutionalism.

This leads in Chapter 4 to a discussion of how academic researchers who feature prominently in REF2014 narrative-based impact case studies make sense of being REF impactful and accordingly competitively accountable. This chapter draws on a major survey of academic researchers represented across social science REF sub-panel disciplines and seeks to explore how being REF impactful contributes to change in research praxis at either an individual or a collective level.

In Chapter 5, I consider observational and interview data pertaining respectively to REF evaluators in the context of one institutional mock-REF exercise, and to data which record the experiences of REF2014 panel members - both academic and user-assessors. This 
chapter reveals the multiple limitations of impact evaluation as relates to the absence of evidence and theory set against an abundance of narrative-based artifice, and the contribution of REF impact in producing 'a new form of scholarly distinction'.

Chapter 6 then turns to the perceptions of a group identifiable as a major beneficiary of academic research, the UK parliamentary community. The accounts of parliamentarians are explored to locate the efficacy of this 'new form of scholarly distinction' and the extent to which competitive accountability facilitates, augments or conversely inhibits or damages the interface between research producer and research user.

Competitive accountability is then explored in Chapter 7 in the context of 2018's major institutional crises in the UK related to issues of vice-chancellors' pay and widescale industrial action prompted by a pensions dispute. Chapter 7 explores how competitive accountability is used as justification by university leaders for their bloated salaries, while the historically unprecedented industrial action committed by academics across many UK universities is used as an example of the potential of critical activism against the perniciousness of market intensification in the UK higher education sector.

Finally, in Chapter 8, I draw out what are ten paradoxes of competitive accountability that highlight the absurdity of current research praxis by academics in UK universities and which I propose establish a strong rationale for the rejection of an existing model of research practice under the UK's performance management and evaluation regime and a motivation for the reconceptualization of academics as public intellectuals and the reassertion of their public legitimacy and social value.

\section{NOTE}

1. For reasons, especially in the contemporary UK context, of the visibility and eligibility required of output and evaluation demands. To step outside of the REF cycle for instance would be to commit career suicide, where identity, status and acceptance as a researcher are bound by a contribution to evaluation. 